Received: 13 April 1995

Accepted: 14 July 1995

J. F. Bion (区) - M. Manji University Department of Anaesthesia and Intensive Care,

The Queen Elizabeth Hospital

Edgbaston, Birmingham

B $152 \mathrm{TH}, \mathrm{UK}$

The risks of transporting critically ill patients within or between hospitals are well known [1-6]. The most common problem is failure to control cardiorespiratory function, resulting in physiological instability with impaired tissue oxygenation. This may have serious consequences. For example, as many as $50 \%$ of head-injured patients may be exposed to significant risk of intracranial hypertension, even during intrahospital transfer [5]. Brain injury will be exacerbated by hypoxaemia and hypotension, which have been documented in $15 \%$ and $7 \%$, respectively, of patients transferred to a regional neurosurgical service [7]. Indeed, no matter how short the distance or the time involved, critically ill patients are inevitably put at greater risk when they are moved as equipment deficiencies and inexpert attendants diminish the level of care they receive [6]. There are several strategies that we should adopt to reduce these risks.

\section{Prediction of risk}

Can we identify patients who might deteriorate during transfer? Waydhas and colleagues [1] (this issue) describe the results of a prospective observational study evaluating the effects on respiratory function of intrahospital transfer of mechanically ventilated patients to the operating theatre or radiology department. Ventilation was main- tained with an Oxylog emergency ventilator - a time-cycled, constant volume ventilator capable of delivering the pre-set tidal volume despite changes in respiratory mechanics. Defined as a reduction of $20 \%$ or more in the $\mathrm{PO}_{2} \mathrm{FiO}_{2}$ ratio, a major deterioration of respiratory function was observed in nearly $43 \%$ of transfers; in 10 patients $(20 \%)$, this condition persisted for more than $24 \mathrm{~h}$. The variable most closely related to this deterioration was the prior requirement for positive end expiratory pressure (PEEP). There was no apparent relationship with severity of illness, age, transfer for surgery, initial $\mathrm{PO}_{2}$ or transport time. The authors did not, however, check arterial blood gases after stabilising the patients on the transport ventilator; thus the timing and cause of the increase in shunt cannot be identified from this article. PEEP restores lung volumes - most importantly, the functional residual capacity. Measuring and controlling PEEP accurately during transport is not easy, particularly when changes in patient posture [8], sedation and pulmonary blood flow may contribute covertly to changes in shunt. Portable ventilators are unable to duplicate exactly the gas flow pa ${ }^{++}$erns of modern ICU ventilators, and cannot accurately provide inverse ratio ventilation (IRV), which creates intrinsic PEEP. Changing ventilators may reverse beneficial redistribution of lung water by PEEP [9], the reestablishment of which may take time [10]. It should not be overlooked during transfer, that PEEP is not without adverse effects: it may contribute to impaired tissue perfusion through a reduction in cardiac output. Evidently, patients receiving PEEP to reduce pulmonary shunting require particular care before and during transport, and the article by Waydhas et al. identifies a simple marker of risk.

Are measures of severity of illness useful general predictors of risk of complications during transfer? Scoring systems have been shown to be helpful for auditing interhospital transfers [6, 11]. Physiologically based systems such as Apache II can reveal beneficial effects of therapy during transfer [11]; however, they are also sus- 
ceptible to misinterpretation when the normal physiological response to the stimulus of movement in less severely ill patients results in tachycardia and hypertension sufficient to increase the score for these components $[11,12]$. Two paediatric studies provide conflicting conclusions about the value of severity stratification. Kanter et al. [13] suggest that more severely ill children are at increased risk for complications during transfer, and that low-risk patients can be transferred safely by staff from the referring hospitals. Orr et al. [14], using a specialist paediatric transport team, were unable to find a relationship between PRISM score and transport interventions, and also found that referral PRISM scores underestimated those calculated by the specialist team, an important point of scoring systems are to be used for identifying prior risk over the telephone. It seems likely that high-quality care will abolish the relationship between severity of illness and risk of complications, and paradoxically scoring systems may therefore only be of value in predicting the risk of inexpert transfers.

\section{Risk-benefit assessment}

When patients are transferred for diagnostic investigations such as radiology, will a positive or negative result alter patient management and outcome? Indeck et al. [4] demonstrated that management was altered in only $24 \%$ of their patients within $48 \mathrm{~h}$ of performance of diagnostic test requiring transfer to another department, although $68 \%$ of them underwent potentially serious physiologic changes during transport. Decisions to transfer patients from the secure environment of the ICU should be made only by experienced senior staff.

\section{Timing of transfer}

It is well recognised that in both primary and secondary transport patients should be physiologically stable before transfer. However, a balance must be struck between maintaining stability and administering specific treatments in the receiving hospital. Postponing treatment is a substantial risk factor for multiple organ failure [15] and intensive care mortality [16]. A specialist transport team is more likely to get this balance right and to be able to continue providing expert life support during transfer, for the benefit of the disordered physiology [11].

\section{Quality control and standards}

The most significant determinant of quality of care during transport is the training and expertise of the attendant $[6,11]$. Equipment for monitoring and providing organsystem support is obviously important, but miniaturisation has resolved many of the problems associated with lack of space, and newer monitors are less susceptible to movement artifact. Funding, training, and retaining a specialist transport team is expensive, and health care rationing in countries like the UK results in a high interhospital transfer rate [17] and inadequate resources for secondary transport [18]. Indeed, the variations in funding for emergency care in Europe are a source of concern [19]. France and Germany perform better in this respect. In France the Service d'Aide Medicale Urgente (SAMU) provides a comprehensive transport and retrieval system that is also accessible by the general public through the telephone system, allowing direct contact with a doctor trained in resuscitation; medical staff attend emergency calls and control the transfer [20]. We should not allow variations in health care funding to determine standards of care in Europe. Standards should be based on objective evaluation of the scientific literature, and reports by working groups in the USA, Australasia and the UK either have been published [21, 22] or are in progress [23]. This is an appropriate time for the European Society of Intensive Care Medicine to coordinate evidence-based recommendations on standards for intra- and interhospital transport of critically ill patients.

\section{References}

1. Waydhas C, Schneck G, Duswald KH (1995) Deterioration of respiratory function after intra-hospital transport of critically ill surgical patients. Intensive Care Med 21:748-789

2. Rutherford WF, Fisher CJ (1986) Risk associated with in-house transportation of the critically ill. Clin Res 414A

3. Bramam SS, Dunn SM, Amico CA, Millman RP (1987) Complication of intrahospital transport in critically ill patients. Ann Intern Med 107:469-473
4. Indeck M, Peterson S, Smith J, Brotman S (1988) Risk, cost and benefit of transporting ICU patients for special studies. J Trauma 28:1020-1025

5. Andrews PJD, Piper IR, Dearden NM, Miller JD (1990) Secondary insults during intrahospital transport of head-injured patients. Lancet 335:327-330

6. Bion JF, Wilson IH, Taylor PA (1988) Transferring critically ill patients by ambulance: audit by sickness scoring. BMJ 296:170
7. Gentleman D, Jennett B (1990) Audit of transfer of unconscious head-injured patients to a neurosurgical unit. Lancet 335:330-334

8. Ibanez J, Rauric JM (1982) Normal value of functional residual capacity in the sitting and supine position. Intensive Care Med 8:173-177 
9. Miller WC, Rice DL, Unger KM, Bradley BL (1981) Effect of PEEP on lung water content in experimental non-cardiogenic pulmonary edema. Crit Care Med 9:7-9

10. Katz JA, Ozanne GM, Zinn SE, Fairley $\mathrm{HB}$ (1987) Time course and mechanism of lung-volume increase in PEEP in acute pulmonary failure. Anesthesiology $54: 9-16$

11. Bion JF, Edlin SA, Ramsay G, McCabe S, Ledingham IMA (1985) Validation of a prognostic score in critically ill patients undergoing transport. BMJ 291:432

12. Insel $\mathrm{J}$, Weissman $\mathrm{C}$, Kemper $\mathrm{M}$, Askanzi J, Hyman AI (1986) Cardiovascular changes during transport of critically ill and postoperative patients. Crit Care Med 14:539-542

13. Kanter RK, Tompkins JM (1989) Adverse events during interhospital transport: Physiologic deterioration associated with pretransport severity of illness. Pediatrics $84: 43-48$
14. Orr RA, Venkataraman ST, Cinoman MI, Hogue BL, Singleton CA, McCloskey KA (1994) Pretransport pediatric risk of mortality (PRISM) score underestimates the requirement for intensive care or major interventions during interhospital transport. Crit Care Med 22:101 - 107

15. Henao FJ, Daes JE, Dennis RJ (1991) Risk factors for multiorgan failure: a case control study. J Trauma 31:74-80

16. Purdie JM, Ridley SA, Wallace PM (1990) Effective use of regional intensive care units. BMJ 300:79-81

17. Bion JF (1995) Rationing intensive care. BMJ 310:682-683

18. Wright IH, McDonald JC, Rogers PN, Ledingham IMA (1988) Provision of facilities for secondary transport of seriously ill patients in the United Kingdom. BMJ 296:543-545

19. Bossaert L (1993) The complexity of comparing different EMS system survey of Emergency. Medical Scrvices in Europe. Ann Emerg Med 22:99-102
20. Huguenard P, Niemeyer E, Herve C, Metrot J, Desfemmes C, Hrouda $P$ (1984) Justification de l'aide médicale urgente. Convergences Médicales 3: $113-116$

21. Guidelines Committee of the American College of Critical Care Medicine, Society of Critical Care Medicine and American Association of Critical Care Nurses Transfer Guidelines Task Force (1993) Guidelines for the transfer of critically ill patients. Crit Care Med 21:931-937

22. Australia and New Zealand College of Anaesthetists and Australasian College for Emergency Medicine (1992) Minimum standards for transport of the critically ill. Australia and New Zealand College of Anaesthetists Policy Document No 23

23. Oakley PA (1994) The need for standards for inter-hospital transfer. Anaesthesia 49:565-566 